\title{
Entrega absoluta à trepidação do texto
}

\section{Constança Carvalho Homem}

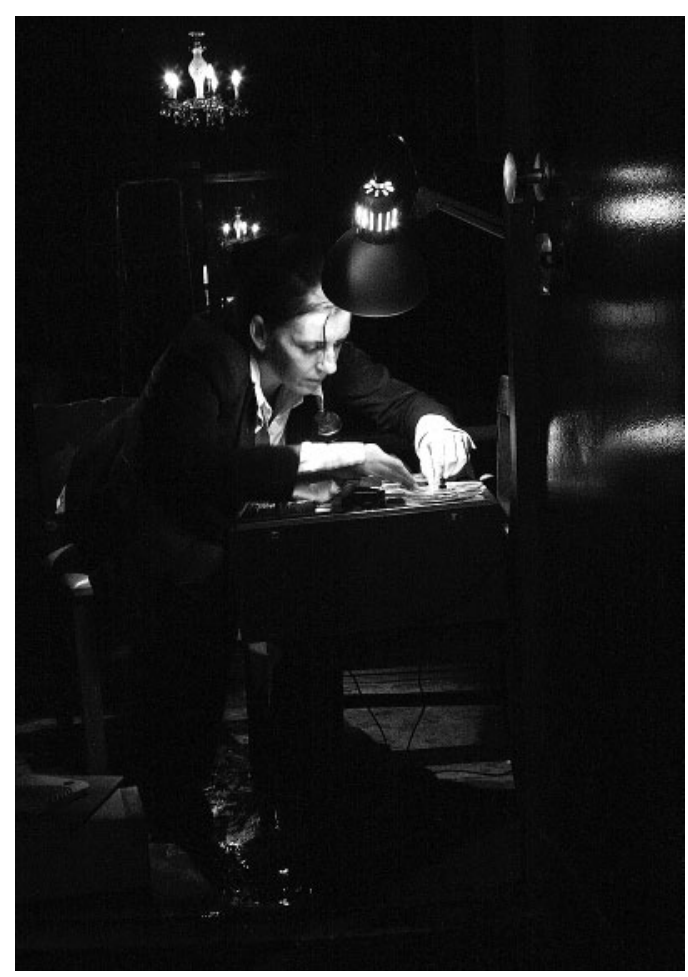

"Brinca com a tua dificuldade. [...] Se a usares, ela tornase interessante." Foi esta indicação que Mónica Calle deu a uma das actrizes no workshop que serviu de base a Esta noite improvisa-se no Cais do Sodré, a partir de Pirandello, apresentado ao público em Novembro de 2009. Enquanto participante da primeira edição do workshop, fui anotando esta e outras indicações, como coisa útil, sem ter bem a consciência da sua relevância; foi mais tarde, ao reler, que percebi ter anotado não apenas instruções, mas fundamentos de uma prática artística consolidada. É a partir dessas notas que, citando como se abrisse uma gramática, conduzirei a justificação da Menção Especial que o júri da APCT atribuiu a esta companhia.

Pergunto: porque vamos à Casa Conveniente, qual é, efectivamente, a conveniência da casa? Creio que a resposta é a persistência com que abraça um teatro que alia músculo verbal e exigência interpretativa raros a um impreterivel, generoso desígnio de repensar formas e práticas. De facto, o teatro da Casa Conveniente é do domínio do não-domesticado, do improvável. Rarefeito naquelas que são as linguagens e materialidades convencionadas, uma insinuação de luz, um rudimento cenográfico servem quase sempre essa preocupação maior que é pôr-se à mercê do texto. "Não representem, usemse", disse a Mónica a certa altura, e é talvez essa a

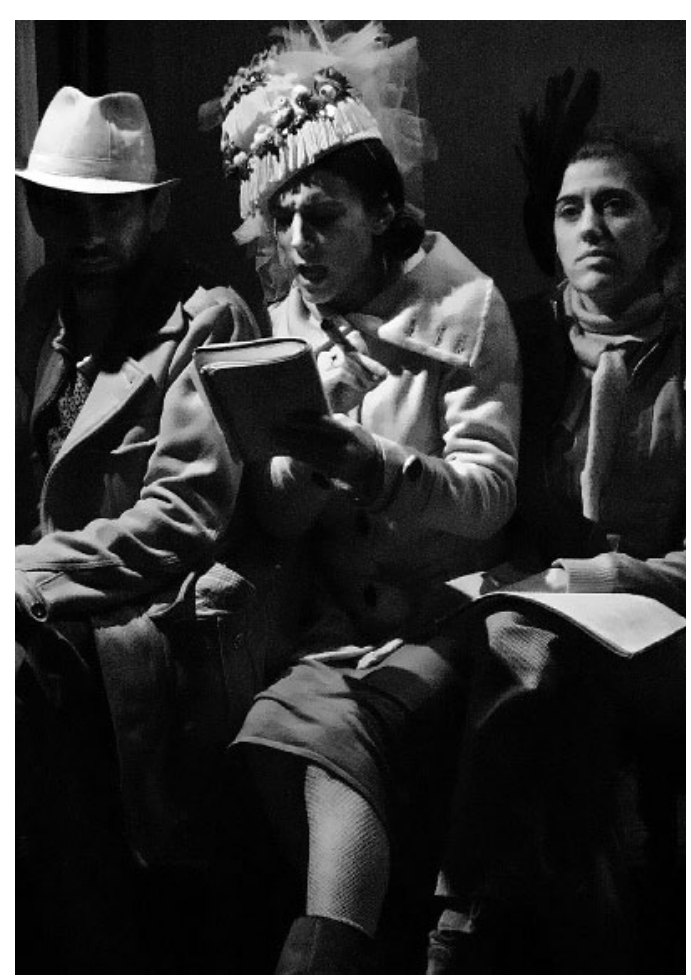

Ouves? A tempestade, sobre A ultima gravação de Krapp, enc. Mónica Calle, Casa Conveniente, 2009 (Mónica Calle), fot. Bruno Simão.

Esta noite improvisa-se no Cais do Sodré, a partir de Pirandello enc. Mónica Calle, Casa Conveniente, 2009 (David Pereira Bastos, Ana Ribeiro e Mónica Garnel), fot. Bruno Simão.

característica mais reconhecivel no trabalho dos actores que habitam a Casa: uma entrega resoluta à trepidação do texto, muitas vezes acompanhada de uma partitura física estrita, que pode ser simples reserva, constrição, gesto mecanizado, explosão. Detecta-se uma intenção de maleabilidade ao preencher o texto, um alheamento consciente face tanto a didascálias como a tradições e modalidades de o veicular na cena, o que obriga os intérpretes a suspender qualquer íntima tentação de se apropriar dele de forma cómoda ou rotineira. É que "um actor não pode ser auto-complacente nem autoindulgente" e em poucos sítios como neste alguém o afirma e o procura de forma tão definitiva.

Uma das maiores virtudes do trabalho desta estrutura é, creio eu, a vontade de expor o que normalmente se protege. Na Casa Conveniente tem-se a noção de que o parto está muitas vezes em curso ao longo da carreira, de que a construção do espectáculo pode constituir o próprio espectáculo. Foi assim nas duas criações mais recentemente concebidas em regime de workshop: A última ceia ou sobre 0 cerejal, a partir de Tchekov, de 2007, e justamente Esta noite improvisa-se no Cais do Sodré. Se no primeiro não havia, por exemplo, uma distribuição fixa dos papéis masculinos, no segundo houve até espaço para que Mónica Calle, fora da jurisdição do
Constança Carvalho Homem é Bolseira da FCT (Fundação para a Ciência e a Tecnologia) e doutoranda da

Faculdade de Letras da Universidade do Porto. 


\section{Ouves? A tempestade, sobre Minetti, \\ enc. Mónica Calle, \\ Casa Conveniente, 2009 \\ (David Pereira Bastos),}

fot. Bruno Simão.

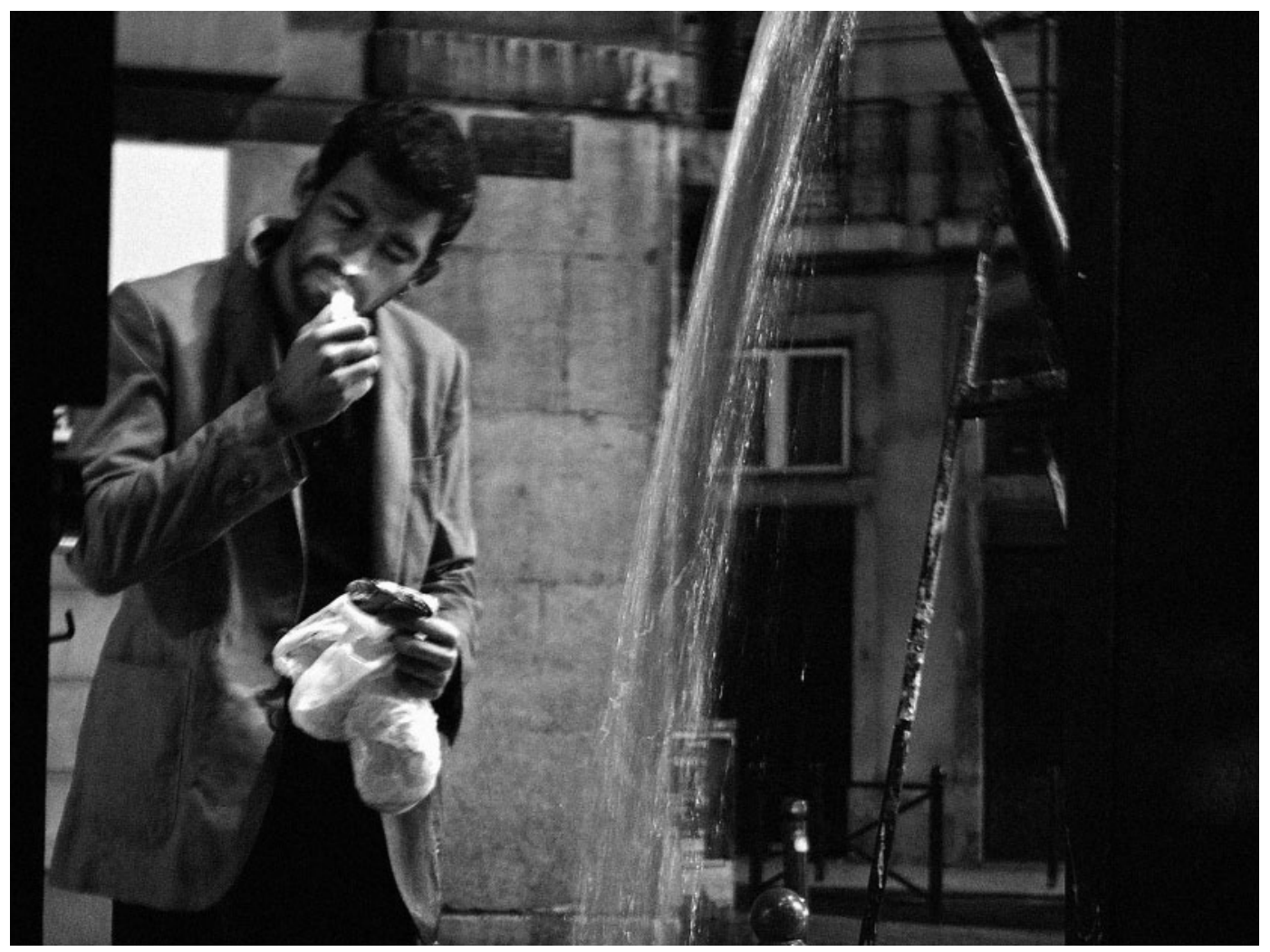

Doutor Hinkfuss mas em plenas funções pedagógicas, pudesse dirigir os actores em tempo real.

Há, naturalmente, uma dimensão de risco nem sempre mensurável em opções que sacrificam a estabilidade do espectáculo, mas eu diria que o retorno tem sido tanto maior e mais empolgante quanto maior é a transparência do acto criativo. Por outro lado, ao inscrever no espectáculo os gestos, as tentativas, os acidentes próprios de um ensaio, ao permitir que o público aceda ao seu esqueleto, ele transforma-se num objecto até certo ponto documental, precioso repositório de um processo.

Finalmente, creio que é de referir, no trabalho da Casa Conveniente, a urgência em redimensionar os espaços cénico e público, deixando que se interpelem e co-ocorram sem ferir as respectivas independências. A comprová-lo, criações várias em que a porta aberta possibilita o trânsito da acção, a entrada de espectadores curiosos, o entrever da vida nocturna, visiveis mas paralelos porque, e cito uma última vez: "Não quero confundir teatro com realidade, eu acredito que o teatro é outra coisa."

Entre a Casa Conveniente e Mónica Calle a relação é de quase sinonímia. Actriz, encenadora e directora artística da companhia, ela é a face e substância mais cabal da Casa. Protagonizou o acto fundador da estrutura quando, em 1992, numa primeira morada no Cais do Sodré, estreou Virgem doida, a partir de Rimbaud, com encenação de Amadeu Neves. Apresentado como "strip-tease teatral em sessões contínuas", o espectáculo conquistou os prémios "Sete de Ouro Revelação de Teatro" do jornal Se7e e "Actriz Revelação" da Associação Portuguesa de Críticos de Teatro e lançou as bases para o seu percurso posterior, marcado pela centralidade do actor-matéria e por um interesse pela "dimensão mais sagrada da palavra", o que talvez ajude a explicar a confluência e assimilação de autores tão diversos como Tchekov, Lobo Antunes, Fassbinder, Beckett, Fiama Hasse Pais Brandão e Thomas Bernhard. Encontrada uma casa mais que provisória, Mónica Calle foi encontrando também um conjunto de intérpretes com quem e para quem cria e que, sob a sua direcção, chegaram provavelmente à asserção mais límpida do seu talento. Falo de Mónica Garnel e Ana Ribeiro, que desde 2000 integram regularmente produções da companhia, e que retive, de forma indelével, depois de espectáculos como Comédia ou a força do hábito ou A última ceia, bem como de David Pereira Bastos, para quem 2009 foi um ano de grande vigor, com interpretações excepcionais em Minetti ou Um retrato do artista quando jovem, Ouves?

A tempestade e Porque não estás contente?, este último uma criação própria. É por causa de todos eles, por causa de espectáculos como Minetti, Esta noite improvisa-se no Cais do Sodré e Manifesto, entre outros, que ao voltar à Casa Conveniente queremos dizer, com Pirandello: "O drama vem agora. Novo, complexo." 